\title{
The Urotensin II System and Carotid Atherosclerosis: A Role in Vascular Calcification
}

\author{
Isabella Albanese ${ }^{1}$, Stella S. Daskalopoulou ${ }^{1}$, Bin Yu ${ }^{1}$, Zhipeng You ${ }^{1}$, Jacques Genest ${ }^{1}$, \\ Alawi Alsheikh-Ali ${ }^{2}$ and Adel G. Schwertani ${ }^{1 *}$ \\ ${ }^{1}$ Cardiology, McGill University Health Center, Montreal, QC, Canada, ${ }^{2}$ Cardiology, College of Medicine, Mohammed Bin \\ Rashid University, Dubai, UAE
}

Background and Aims: The aims of the present study were to determine the expression of urotensin II (UII), urotensin-II related peptide (URP), and their receptor (UT) in stable and unstable carotid atherosclerosis, and determine the effects of UII on human aortic smooth muscle cell (SMCs) calcification.

Methods and Results: We examined UII, URP, and UT protein expression in 88 carotid

OPEN ACCESS

Edited by:

Douglas G. Johns,

Merck \& Co., USA

Reviewed by:

Ryusuke Takechi,

Curtin University, Australia

Gaetano Santulli,

Columbia University, USA

Abolfazl Zarjou,

University of Alabama at Birmingham,

USA

*Correspondence:

Adel G. Schwertan

adel.schwertani@mcgill.ca

Specialty section:

This article was submitted to

Cardiovascular and Smooth Muscle

Pharmacology,

a section of the journal

Frontiers in Pharmacology

Received: 10 February 2016

Accepted: 20 May 2016

Published: 07 June 2016

Citation:

Albanese I, Daskalopoulou SS, Yu B,

You Z, Genest J, Alsheikh-Ali A and

Schwertani AG (2016) The Urotensin II

System and Carotid Atherosclerosis:

A Role in Vascular Calcification.

Front. Pharmacol. 7:149

doi: 10.3389/fphar.2016.00149 endarterectomy specimens using immunohistochemistry. Expression of UII, URP, and UT was more evident in unstable compared to stable plaques $(P<0.05)$. Multivariate Spearman correlation analyses revealed significant positive correlations between UII, URP and UT overall staining and presence of calcification, severity of stenosis and inflammation $(P<0.05)$. Subjects undergoing carotid endarterectomy had significantly higher plasma UII levels, as assessed by ELISA, when compared with normolipidemic healthy control subjects $(P<0.05)$. Incubation of human aortic SMCs cultured in phosphate media with varying concentrations of UII resulted in a significant increase in calcium deposition and alkaline phosphatase activity. UII also significantly increased $\beta$-catenin translocation and expression of ALPL, BMP2, ON, and SOX9 $(P<0.05)$. Incubation of cells with phosphate medium alone increased the expression of the pre-UT and mature UT $(P<0.01)$, and addition of UII had a synergistic effect on pre-UT protein expression $(P<0.001)$ compared to phosphate medium alone.

Conclusions: Upregulation of UII, URP, and UT in unstable carotid endarterectomy plaques and plasma, and the stimulatory effect of UII on vascular smooth muscle cell calcification suggest that the UII system may play a role in the pathogenesis of vascular calcification and stability of atherosclerosis.

Keywords: immunohistochemistry, calcium, URP, UT, UII, urotensin II, urotensin II-related peptide, smooth muscle cells

\section{INTRODUCTION}

Atherosclerosis is a leading cause of death in Western societies, and is a major contributor to several cardiovascular diseases such as myocardial infarction (MI) and stroke (Yusuf et al., 2002). Turbulent blood flow is a known endothelial cell activator, thus contributing to the formation of atherosclerotic plaques mainly in bifurcated blood vessels such as carotid arteries (Tsaousi et al., 2011). Endothelial dysfunction due to alterations in blood flow and/or vascular injury is considered 
the first step in the pathogenesis of atherosclerosis (Libby, 2012). The latter is characterized by the accumulation of lipids and fibrous lesions in large arteries (Lusis, 2000). Vascular calcification occurs in advanced atherosclerotic lesions, and is a marker of atherosclerosis associated with cardiovascular pathologies such as hypertension, congestive heart failure, hypertrophy, ischemia, myocardial infarction, and stroke (Johnson et al., 2006; Demer and Tintut, 2008). Long-term outcomes are worse in patients with calcified blood vessels (Shao et al., 2010).

Urotensin II (UII) is a potent vasoactive peptide, first isolated in the teleost fish Gillichthys mirabilis (Pearson et al., 1980), and subsequently identified in human and other species (Coulouarn et al., 1998; Ames et al., 1999; Elshourbagy et al., 2002). UII possess a wide range of vasoactive properties depending on the type of vessel and species (Itoh et al., 1988; Douglas et al., 2000; Affolter and Webb, 2001). Urotensin II related peptide (URP) is the endogenous and functional ligand for UII receptor (UT) in rats and mice, and its expression has been shown to be elevated in essential hypertension (Prosser et al., 2008). UII and UT have been associated with multiple cardiovascular pathologies such as congenital heart disease (Simpson et al., 2006), ischemic reperfusion injury (Prosser et al., 2008), atrial fibrillation (Zhang et al., 2009), and congestive heart failure (Douglas et al., 2002; Dschietzig et al., 2002; Dai et al., 2008). We were the first to demonstrate that atherosclerotic lesions of the human carotid arteries and aorta have increased expression of UII and UT compared to healthy vessels (Bousette et al., 2004). In recent years, significant evidence has begun to emerge about the role of the UT receptor system in atherosclerosis (Ross et al., 2010). We have demonstrated that both the UT antagonist SB657510A and UII gene deletion in atherosclerotic mice can lead to several beneficial effects, including reductions in serum cytokines, inflammatory adipokines, and adipogenesis, as well as improvement in hypertension and glucose tolerance (You et al., 2012). UT antagonist SB657510A also attenuates diabetesassociated plaque development (Watson et al., 2013). Despite the strong evidence implicating UII in atherosclerosis and associated features such as hyperlipidemia, there are currently no studies demonstrating a direct role for UII in vascular calcification.

In this study, we aimed to assess the tissue expression of UII, URP, and UT, and the plasma levels of UII in relation to carotid plaque stability, and presence of calcification, inflammation, and lipid. We also determined the effect of UII on human aortic SMCs differentiation, calcification, alkaline phosphatase (ALP) enzyme activity, and signaling pathway of genes associated with osteogenesis.

\section{MATERIALS AND METHODS}

\section{Tissue Collection}

Eighty-eight carotid plaque specimens were freshly collected from patients who underwent carotid endarterectomy procedures between 2009 and 2011. Summary of clinical data for these patients is shown in Table 1. Venous blood

Abbreviations: SMCs, Smooth muscle cells. samples were also collected from 55 of these patients (38 stable and 17 unstable) as well as 44 normolipidemic healthy control subjects into EDTA-containing tubes and were centrifuged and stored at $-80^{\circ} \mathrm{C}$ for future analysis of plasma UII and biochemical analysis in batches (Table 2). The degree of carotid stenosis was assessed using 3D carotid ultrasound (Philips iu22). This study was approved by the McGill Ethics Institutional Research Board, and all patients provided written informed consent.

TABLE 1 | Clinical characteristics of the carotid endarterectomy specimens included in the immunohistochemical study.

\begin{tabular}{|c|c|c|c|}
\hline Parameter & Stable $(N=57)$ & $\begin{array}{l}\text { Unstable } \\
(N=31)\end{array}$ & $\begin{array}{l}\text { Statistical } \\
\text { difference }\end{array}$ \\
\hline Age (years) & $68.74 \pm 10.05$ & $71.42 \pm 7.61$ & NS \\
\hline Sex (Number of females) & $18(31.6 \%)$ & $6(19.4 \%)$ & NS \\
\hline $\mathrm{BMI}\left(\mathrm{kg} / \mathrm{m}^{2}\right)$ & $26.95 \pm 3.97$ & $26.65 \pm 4.79$ & NS \\
\hline $\mathrm{TC}(\mathrm{mmol} / \mathrm{L})$ & $3.68 \pm 1.04$ & $3.72 \pm 1.08$ & NS \\
\hline $\mathrm{TG}(\mathrm{mmol} / \mathrm{L})$ & $1.72 \pm 0.96$ & $1.70 \pm 0.69$ & NS \\
\hline $\mathrm{HDL}(\mathrm{mmol} / \mathrm{L})$ & $0.96 \pm 0.27$ & $0.93 \pm 0.27$ & NS \\
\hline LDL (mmol/L) & $2.00 \pm 0.95$ & $2.01 \pm 0.93$ & NS \\
\hline Total Chol/HDL & $4.04 \pm 1.36$ & $4.13 \pm 1.06$ & NS \\
\hline ApoB (g/L) & $0.74 \pm 0.24$ & $0.77 \pm 0.24$ & NS \\
\hline ApoA1 (g/L) & $1.23 \pm 0.24$ & $1.26 \pm 0.30$ & NS \\
\hline ApoB/ApoA1 & $0.62 \pm 0.23$ & $0.63 \pm 0.20$ & NS \\
\hline $\mathrm{SBP}(\mathrm{mmHg})$ & $141.2 \pm 16.39$ & $139.7 \pm 17.60$ & NS \\
\hline $\mathrm{DBP}(\mathrm{mmHg})$ & $70.07 \pm 9.99$ & $64.14 \pm 9.98$ & NS \\
\hline Stenosis (\%) & $84.5 \pm 10.51$ & $86.07 \pm 8.94$ & NS \\
\hline Diabetes (Number of patients) & $19(33.3 \%)$ & $8(25.8 \%)$ & NS \\
\hline
\end{tabular}

BMI, body mass index; TC, total cholesterol; TG, triglycerides; $H D L$, high-density lipoprotein; LDL, Iow-density lipoprotein; ApoB, Apolipoprotein B; ApoA1, Apolipoprotein A1; SBP, systolic blood pressure; DBP, diastolic blood pressure; NS, not significant.

TABLE 2 | Clinical characteristics of the carotid endarterectomy patients vs. control subjects included in the ELISA study.

\begin{tabular}{lccc}
\hline Parameter & $\begin{array}{c}\text { Carotid patients } \\
(\mathbf{N}=\mathbf{5 5})\end{array}$ & $\begin{array}{c}\text { Control } \\
(\mathbf{N}=\mathbf{4 4})\end{array}$ & $\begin{array}{c}\text { Statistical } \\
\text { difference }\end{array}$ \\
\hline Age (years) & $68.98 \pm 9.30$ & $41.41 \pm 15.37$ & $P<0.0001$ \\
Sex (Number of females) & $15(27.3 \%)$ & $20(45.5 \%)$ & NS \\
BMl (kg/m $\left.{ }^{2}\right)$ & $26.91 \pm 4.01$ & $23.02 \pm 3.29$ & $P<0.0001$ \\
TC (mmol/L) & $3.68 \pm 1.01$ & $4.90 \pm 1.09$ & $P<0.0001$ \\
TG (mmol/L) & $1.74 \pm 0.89$ & $1.46 \pm 0.76$ & NS \\
HDL (mmol/L) & $0.95 \pm 0.26$ & $1.23 \pm 0.22$ & $P<0.0001$ \\
LDL (mmo//L) & $1.97 \pm 0.94$ & $1.16 \pm 0.38$ & $P<0.0001$ \\
Total Chol/HDL & $4.08 \pm 1.26$ & $4.12 \pm 1.27$ & NS \\
ApoB (g/L) & $0.75 \pm 0.24$ & $1.03 \pm 0.25$ & $P<0.0001$ \\
SBP (mmHg) & $140.8 \pm 18.3$ & $117.2 \pm 16.8$ & $P<0.0001$ \\
DBP (mmHg) & $69.2 \pm 10.0$ & $72.3 \pm 10.5$ & NS \\
Statins (Number of patients) & $(38 / 55)$ & $(4 / 44)$ & $P<0.0001$ \\
\hline
\end{tabular}

$B M I$, body mass index; TC, total cholesterol; TG, triglycerides; HDL, high-density lipoprotein; LDL, Iow-density lipoprotein; ApoB, Apolipoprotein B; ApoA1, Apolipoprotein A1; SBP, systolic blood pressure; DBP, diastolic blood pressure; NS, not significant. 


\section{Immunohistochemistry}

The paraffin-embedded carotid specimen blocks were cut into 4$5 \mu \mathrm{m}$ sections using a microtome and placed on glass slides. The immunohistochemical technique used here had previously been described (Pearson et al., 1980). Five sections were examined per lesion (for each antiserum). A total of 6 images were analyzed per section.

The antibody used for the URP immunostaining studies was purchased from Phoenix Pharmaceuticals H-071-17, and does not cross react with human UII. The antibodies against UII and UT used have been previously described (Douglas et al., 2002; Bousette et al., 2006b). Additional sections were stained for $\alpha$-smooth muscle actin (smooth muscle marker, Cedarlane CLT9000, 1/500) and Mac-2 (macrophage marker, Cedarlane CL8942AP, 1/2500).

Carotid plaques were semi-quantitatively assessed blindly by two independent vascular pathologists for calcification, fibrosis, inflammation, lipid, microvessels, hemorrhage, thrombus, cap infiltration with inflammatory cells and overall plaque instability, using well-established scales, including the widely used American Heart Association (AHA) plaque classification (Stary et al., 1995; Lovett et al., 2004). All plaques were classified as either AHA type $\mathrm{V}$ or type $\mathrm{VI}$ and lesions that were classified as type $\mathrm{V}$ were considered as stable and those classified as type VI, considered unstable. Immunostaining was assessed using Image $\mathrm{J}$ by two independent observers.

\section{Measurement of Circulating UII Levels}

In all 55 subjects who underwent carotid endarterectomy, as well as in the normolipidemic healthy control subjects UII levels were measured using human urotensin II ELISA kit (PromoKine, catalog number: PK-EL-K101, Germany) in accordance with the manufacture's manual. The specificity of the ELISA kit had previously been described (Al Kindi et al., 2014).

\section{In vitro Studies}

\section{In vitro Calcification Experiments}

Human aortic SMCs were cultured in Medium-231 (ThermoFisher) including Smooth Muscle Cell Differentiation Supplement (ThermoFisher) in the presence of varying concentrations of UII $(0,10,50,100 \mathrm{nM}), 100 \mathrm{nM} \mathrm{UII}+$ varying concentrations $(0,1,10 \mu \mathrm{M})$ of UT antagonist SB657510A (kindly offered by GSK, USA), 0, 10, 50, $100 \mathrm{nM}$ of URP, and 100 $\mathrm{nM}$ URP $+10 \mu \mathrm{M}$ of UT antagonist SB657510A and $100 \mathrm{nM}$ of URP for 2 weeks. Calcium content was measured using the Arsenazo III method. Cells were assayed in triplicates in 96 well plates.

Briefly, cells were washed three times with $2 \mathrm{ml}$ PBS (Phosphate-Buffered Saline, Life Technologies) per well for $5 \mathrm{~min}$ each wash. Cells were then incubated with $250 \mu \mathrm{L}$ of $0.6 \mathrm{~N} \mathrm{HCl}$ for $24 \mathrm{~h}$ at room temperature (RT) and $\mathrm{Ca}^{2+}$ was measured using colorometric Arsenazo III method. To the remaining cells, protein lysis buffer was added $(100 \mu \mathrm{L}$ of $0.1 \mathrm{~N} \mathrm{NaOH}$ with $0.1 \%$ SDS) for $20 \mathrm{~min}$ at RT. Cells were transferred to Eppendorf tubes and centrifuged for $5 \mathrm{~min}$ at $4^{\circ} \mathrm{C}$ at $15,000 \mathrm{rpm}$. The supernatants were removed and stored at $-80^{\circ} \mathrm{C}$ for subsequent protein measurement, for the normalization of $\mathrm{Ca}^{2+}$ measurements.

\section{In vitro ALP Assay}

SMCs were incubated for 7 days in the following conditions: DMEM alone. Forty-eight hours after incubation under the different media conditions, ALP activity in human aortic smooth muscle cell media was assessed using Alkaline Phosphatase Activity Colorimetric Assay Kit (BioVision) according to manufacturer protocols. Eighty microliters of media was added to each well. Eighty microliters of fresh media were also added to separate wells to use as a sample background control. Twenty microliters of Stop Solution was added to the background control. Then, $50 \mu \mathrm{L}$ of $5 \mathrm{mM}$ p-nitrophenyl phosphate (pNPP) was added to each well and reaction was incubated for $1 \mathrm{~h}$ at $25^{\circ} \mathrm{C}$, protected from light. Twenty microliters of Stop Solution was added to each sample and standard well to stop the reactions. O.D. was measured at $405 \mathrm{~nm}$ in micro plate reader. Using standard curve, ALP activity in the media of each sample was calculated and is expressed in Glycine Units. Glycine Units are defined as the amount of enzyme causing hydrolysis of $1 \mu \mathrm{mol}$ of pNPP per minute at $\mathrm{pH} 9.6$ and $25^{\circ} \mathrm{C}$.

\section{Effect of Phosphate Medium on UT Protein Expression in SMCs}

SMCs were incubated in either DMEM, DMEM+UII (100 nM), Pi-DMEM (phosphate: $2.6 \mathrm{mmol} / \mathrm{l}$ ), or Pi-DMEM+UII (phosphate: $2.6 \mathrm{mmol} / \mathrm{l}$, UII: $100 \mathrm{nM}$ ) for 7 days. The medium was changed every 2-3 days. After two washes in PBS buffer, the cells were placed in lysis buffer for $15 \mathrm{~min}$ on ice. The solutions were transferred into eppendorf tubes and centrifuged at $8000 \mathrm{rpm}$ for $5 \mathrm{~min}$. UT expression was detected with Western blot (primary antibody dilution 1:1000, and secondary antibody dilution 1:5000). UT antibody used was as previously described (Bousette et al., 2006a).

$G A P D H$ was as internal standard. Image J was used to quantity UT expression.

\section{Effect of UII on SMC Proliferation}

Vascular SMCs were incubated with phosphate medium with or without $10 \mathrm{nM}$ UII for 4 and 7 days. Cells were then fixed in 4\% paraformaldehyde and stained with antiserum to $\alpha$-SMC actin using the avidin-biotin-peroxidase method described above. The numbers of $\alpha$-SMC actin-positive cells were quantified using Image J.

\section{RT-PCR Analyses}

Vascular SMCs were treated with or without $100 \mathrm{nM}$ human UII peptide (Sigma) for $24 \mathrm{~h}$ in osteogenic medium (OSM). Cells in 24-well plate were washed with cold PBS, then total RNA were isolated by using RNeasy mini kit(Qiagen). One microgram RNA was used for the first strand cDNA synthesis using iScript Select cDNA synthesis kit (Bio-Rad), and qPCR performed using Advanced qPCR Master mix HI-ROX(Wisent) on StepOneTM Plus (Applied Biosystems) for various osteogenic mediators. Gene expression level was calculated against a control standard curve generated by housekeeping gene: GAPDH, relative expression level is presented as relative ratio normalized against sample GAPDH level. DMEM medium (DM): Gibco DMEM with high glucose containing 10\% FBS, 1\% Penicillin, 
1\% Streptomycin; Osteogenic medium: full DMEM medium with calcification reagent, $2 \mathrm{mM}$ phosphate buffer and $0.2 \mathrm{mM}$ ascorbic acid. $N=4$ per experiment.

To assess UII, URP, and UT mRNA expression in carotid plaques, total RNAs (total 20 IHC matched samples, stable cases $=10$, unstable cases $=10$ ) were extracted from surgically removed carotid plaques using TRIzol(ThermoFisher) and RNeasy mini kit(Qiagen). First strain cDNAs were synthesized using $1 \mu \mathrm{g}$ total RNA with iScript Select cDNA synthesis kit (BioRad), and qPCR performed using Advanced qPCR Master mix HI-ROX(Wisent) on StepOneTM Plus (Applied Biosystems). GAPDH was used as internal control, relative gene expression was calculated using GeneStudy software (Bio-Rad).

\section{Effect of UII on $\beta$-Catenin Nuclear Translocation}

Vascular SMCs were seeded in duplicates of $100 \mathrm{~mm}$ petri dishes and were pre-incubated in osteogenic medium for 4 days, then UII (100 nM) or URP (100 nM) was added into medium for 20 h. Nuclei were extracted with Nuclear Extract Kit (Active Motif, CA USA, cat\#40010). Nuclear protein was loaded on SDS-PAGE, and $\beta$-catenin was detected by Western blot using a polyclonal antiserum (HPA029159, Sigma). The membranes were probed with antiserum to TFIIB as an internal standard (Santa Cruz).

\section{Statistical Analysis}

Multivariate Spearman analysis was used to assess correlations between UII, URP and UT immunohistochemical stainings with the histologic features of carotid atherosclerosis (degree of stenosis, extent of calcification, fibrosis, inflammation, lipid score, microvessels, hemorrhage, thrombus, and cap instability) and clinical parameters [age, sex, body mass index (BMI), total cholesterol, triglycerides, HDL, LDL, Total Chol/HDL, ApoB, ApoA1, ApoB/ApoA1, stenosis, and blood pressure]. One-way ANOVA was used to assess UII, URP, and UT immunostaining in stable compared to unstable carotid plaques, plasma UII measurements in stable and unstable carotid endarterectomy patients as well as when comparing plasma UII values to controls, and the significance of the differences in SMC calcification and ALP activity for different stimulation conditions. For the clinical comparison of patient populations, unpaired $t$-test was performed to determine the statistical significance of continuous variables between the groups. Fisher's exact test was performed to determine the statistical significance of the categorical variables (sex, hypertension, and diabetes) between the two groups. Statistical analyses were performed using GraphPad Prism software version 6.0d (GraphPad Software Inc., La Jolla, CA, USA). $P<0.05$ was considered significant.

\section{RESULTS}

\section{UII Immunohistochemistry}

UII immunostaining was highest in myointimal cells, followed by media SMCs and foam cells (Figures 1A,E,F). Importantly, UII immunostaining intensity was significantly elevated in activated myointimal cells compared to myointimal cells that were not classified as activated $(P<0.0001)$. Semi-quantitative analyses of UII immunostaining intensity showed that UII immunoreactivity was significantly higher in osteoblast, medial smooth muscle cells and microvessels in unstable compared to stable carotid plaques $(P<0.05$; Figures 1A-D; Supplemental Figure 1). Multivariate Spearman correlation analysis revealed significant correlations between overall UII immunoreactivity and diastolic blood pressure $(r=0.2410 ; P<0.05)$, calcification $(r=0.268 ; P<0.05)$, remodeling $(r=0.339, P<0.01)$, inflammation $(r=0.5077 ; P<0.0001)$, lipid $(r=0.353 ; P<$ $0.001)$, URP immunoreactivity $(r=0.671 ; P<0.0001)$, and UT immunoreactivity $(r=0.440 ; P<0.0001)$.

\section{URP Immunohistochemistry}

URP immunostaining was evident in endothelial, myointimal, medial SMCs, and inflammatory cells. URP was also present in microvascular endothelial cells, foam cells and osteoblasts (Figures 1G-L). Semi-quantitative analyses of URP immunostaining intensity showed that URP immunoreactivity was significantly elevated in endothelial and foam cells of unstable compared to stable plaques $(P<0.05$; Figures $1 \mathrm{G}-\mathbf{L}$; Supplemental Figure 1). Multivariate Spearman correlation analysis revealed significant correlations between overall URP immunoreactivity and calcification $(r=0.261 ; P<0.0127)$, fibrosis $(r=0.276 ; P<0.01)$, remodeling $(r=0.2793 ; P<0.05)$, inflammation $(r=0.489 ; P<0.0001)$, lipid $(r=0.304 ; P<0.01)$, and UT immunoreactivity $(r=0.4 ; P<0.001)$.

\section{UT Immunohistochemistry}

UT cellular expression showed strongest immunostaining in myointimal cells followed by medial SMCs (Figure 1M). Semi-quantitative analyses of UT immunostaining showed no significant differences in stable compared to unstable carotid plaques (Supplemental Figure 1). Multivariate Spearman correlation analysis revealed significant correlations between UT immunoreactivity and BMI $(r=-0.2431 ; P<0.05)$, carotid stenosis $(r=0.2669 ; P<0.05)$, calcification $(r=0.381 ; P<$ $0.001)$, fibrosis $(r=0.2175, P<0.05)$, remodeling $(r=0.297$; $P<0.01)$, and inflammation $(r=0.292 ; P<0.01)$.

Negative control sections immunostained with the nonimmune sera or preabsorped with the respective antigens did not show immunoreaction (Figure 1N).

\section{RT-PCR}

UII, URP, and UT mRNA expression was also assessed in stable and unstable carotid plaques however there was no significant difference between the two groups in any of the three molecules (Supplemental Figure 2).

\section{Plasma UII Levels}

The mean age of the carotid endarterectomy patients included in the measurement of plasma UII was $69.0 \pm 9.3$ years and was significantly higher than the control group ( $41.4 \pm 15.4$ years; $P<0.0001)$. Plasma UII levels were still significantly elevated in carotid endarterectomy patients compared to an age-matched control subgroup $(n=10 ; P<0.0001)$. BMI, LDL, systolic blood pressure, and statin use were significantly higher in the carotid endarterectomy group; while total cholesterol, HDL, and ApoB were significantly lower when compared with that of the 

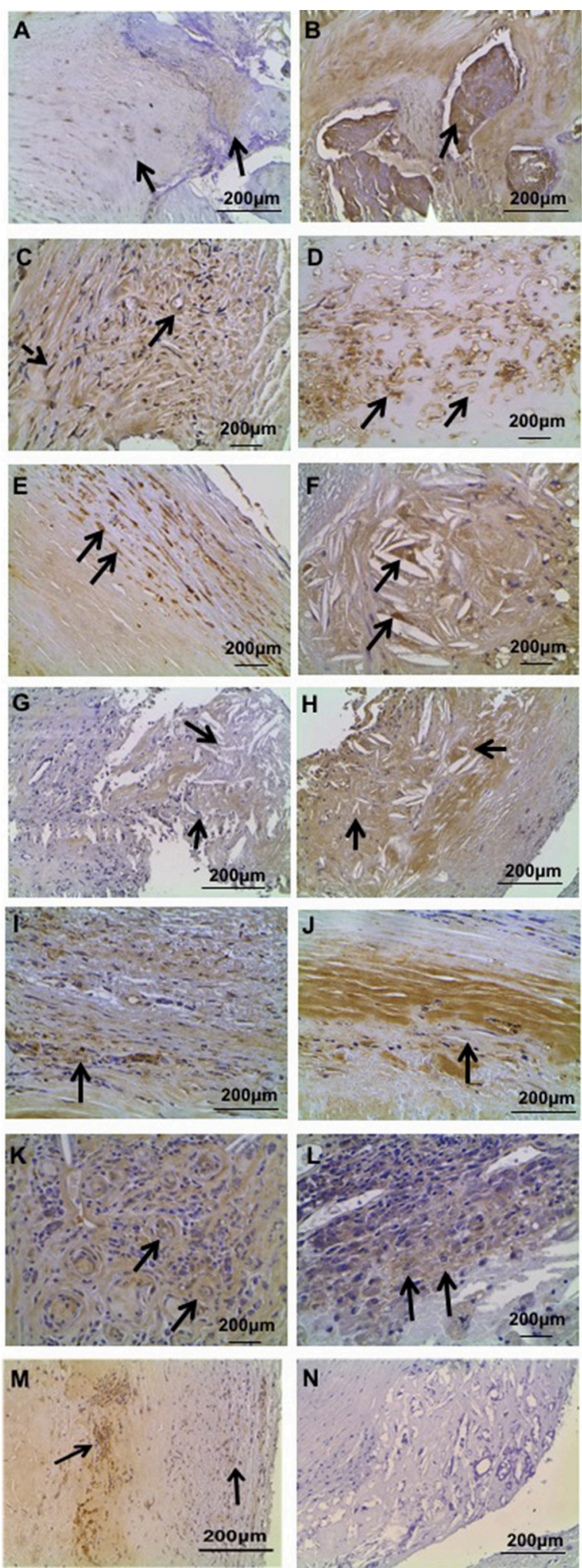

FIGURE 1 | Representative immunohistochemical localization of UII, UT, and URP in human carotid plaque specimens. (A) UII

immunoreactivity in stable carotid plaque: low intensity UII immunostaining

(Continued)

\section{FIGURE 1 | Continued}

in calcification (right arrow) and higher intensity immunostaining in myointimal cells (left arrow). (B) Strong UII immunoreactivity in calcified lesions of unstable carotid plaque. (C) UII staining in microvessels (bold arrow) and myointimal cells (dashed arrow) in stable carotid plaque. (D) Abundant Ull staining in microvessels of unstable plaque. (E) UII staining in media SMCs of unstable plaque. (F) Ull staining in foam cells of unstable plaque. (G) URP immunoreactivity in lipid core and surrounding cholesterol clefts (arrows) in stable carotid plaque. (H) Strong URP immunoreactivity in lipid core of unstable carotid plaque. (I) URP immunoreactivity in fibrosis of stable plaque. (J) Elevated URP immunoreactivity in fibrosis of unstable plaque. (K) URP staining in microvessels of unstable plaque. (L) URP staining in inflammatory cells of unstable plaque. (M) Abundant UT immunoreactivity in myointimal cells (right arrow) and calcium deposition (left arrow). (N) Negative control section of lipid and myointimal cells immunostained with normal serum showing no immunoreactivity.

control group (see Table 2 in Materials and Methods). The mean $( \pm$ SEM) plasma level of UII in carotid endarterectomy patients was significantly elevated $(1194.0 \pm 83.8 \mathrm{pg} / \mathrm{ml})$ compared to the control group $(252.7 \pm 13.9 \mathrm{pg} / \mathrm{ml} ; P<0.0001)$. Plasma UII levels were still significantly elevated in carotid endarterectomy patients compared to an age-matched control subgroup (293.1 \pm $36.92 \mathrm{pg} / \mathrm{ml}, n=10 ; P<0.0001)$. Correlation studies revealed significant correlations between plasma UII and age $(r=0.597, P$ $<0.0001)$, BMI $(r=0.453, P<0.0001)$, systolic blood pressure $(r=0.5130, P<0.0001)$, total cholesterol $(r=-0.35 ; P<$ $0.001)$, triglycerides $(r=0.274, P<0.01)$, HDL $(r=-0.439, P<$ $0.0001)$, and LDL $(r=0.558, P<0.0001)$.

\section{In vitro Data}

Vascular SMCs were incubated in phosphate medium for 2 weeks with varying concentrations of urotensin II $(0,10,50$, $100 \mathrm{nM}$ ). SMC calcification was assessed as the ratio of calcium $(\mu \mathrm{g}) /$ total protein $(\mathrm{mg})$. While supplementation with UII had no significant effect on calcification in normal media, UII appears to be potentiating the effects of phosphate medium on SMC calcification in a dose-dependent manner. Phosphate medium $+100 \mathrm{nM}$ UII had significantly elevated calcium deposition compared to phosphate medium alone $(P=0.0167$, Figure 2$)$. URP at $100 \mathrm{nM}$ concentration showed the strongest stimulation of SMC calcification $(P=0.0376$, Figure 2$)$.

UII and URP stimulatory effect on SMC calcification were significantly reduced in the presence of SB657510A at 10 $\mu \mathrm{M}$ concentration $(P=0.0051$ and $P=0.0191$; respectively, Figure 2). This demonstrates that UII and URP effects on SMC calcification are mediated by signaling through UT.

There was a significantly reduced number of $\alpha$-smooth muscle actin ( $\alpha$-SMA) positive cells 4 days after incubation with phosphate medium containing $100 \mathrm{mM}$ UII compared to phosphate medium alone (data not shown; $P<0.01$ ). At 7 days there was no difference between phosphate medium with or without UII. Moreover, incubation of SMCs with UII as well as URP significantly induced $\beta$-catenin nuclear translocation $(P<$ 0.05) (Figure 3).

Assessment of UT protein expression in SMCs following incubation with phosphate medium revealed a significant increase in protein expression of UT, both mature and immature 


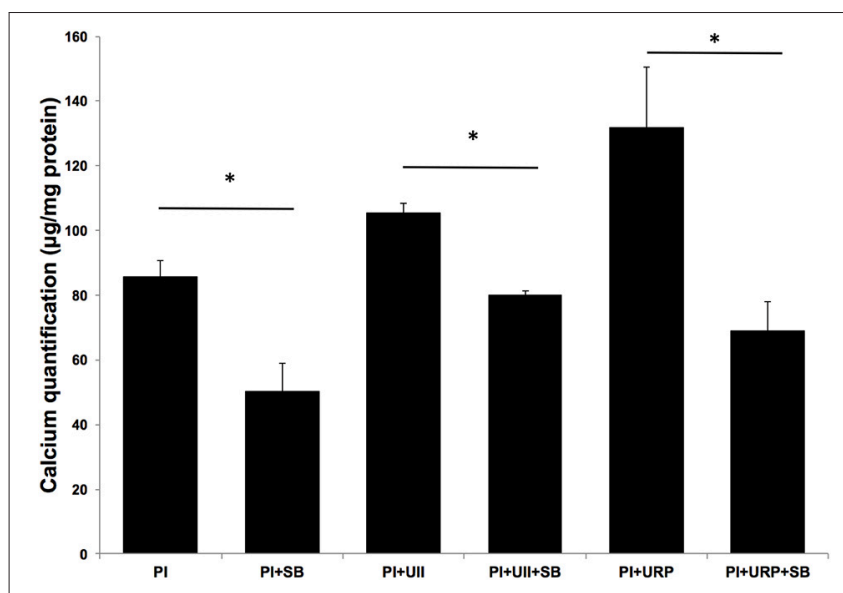

FIGURE 2 | UT Antagonist SB657510A (SB) inhibits UII and URP induced SMC calcification. SMCs were incubated in phosphate medium (PI) for 14 days with $100 \mathrm{nM} \mathrm{UII}$ or $100 \mathrm{nM}$ URP, in the presence and absence of UT antagonist (SB) at concentration $10 \mu \mathrm{M}$. UII and URP stimulatory effect on SMC calcification was abolished in the presence of SB657510A. ${ }^{\star} P<0.05$ ( $n=4$ per experiment).

forms (Figure 4). UII stimulation potentiates the phosphate medium-induced increase in pre-UT as the phosphate medium + UII stimulated cells had significantly elevated expression of preUT compared to phosphate medium alone. However, this was not the case with the mature form of UT, where both phosphate alone and phosphate + UII had significantly elevated mature UT protein expression compared to control conditions.

Incubation of SMCs with phosphate medium significantly increased the expression of various osteogenic mediators. Addition of $100 \mathrm{nM}$ UII for $24 \mathrm{~h}$ significantly augmented the expression of $A L P L, B M P 2$, osteonectin $(\mathrm{ON})$, SOX9, collagen $1 \mathrm{~A} 1$, collagen $3 \mathrm{~A} 1$, and $\alpha-\mathrm{SMC}$ actin $(P<0.01)$ (Figure 5). Expression of Msx2 and Runx2 were not significantly altered.

\section{DISCUSSION}

There is an abundance of evidence showing that carotid atherosclerosis is associated with increased risk of stroke and mortality, particularly in elderly patients (Stary et al., 1995; Störk et al., 2004). There is currently a great need for clinically-relevant serum and tissue biomarkers of carotid atherosclerosis, especially those that can distinguish between stable and unstable carotid plaques. This will contribute to a greater understanding of the pathogenesis of this process and ideally, be a useful tool in the selection of patients for surgical intervention. In this study, we aimed at determining the serum level of UII and tissue expression of UII, URP, and UT in carotid plaque specimens in relation to their stability and to determine if UII plays a role in vascular SMC calcification.

Circulating levels of UII were higher in carotid endarterectomy compared with normal control subjects. We found significant differences in UII and URP immunostaining in unstable compared to stable plaques. Our in vitro studies revealed that UII and URP had a significant dose-dependent

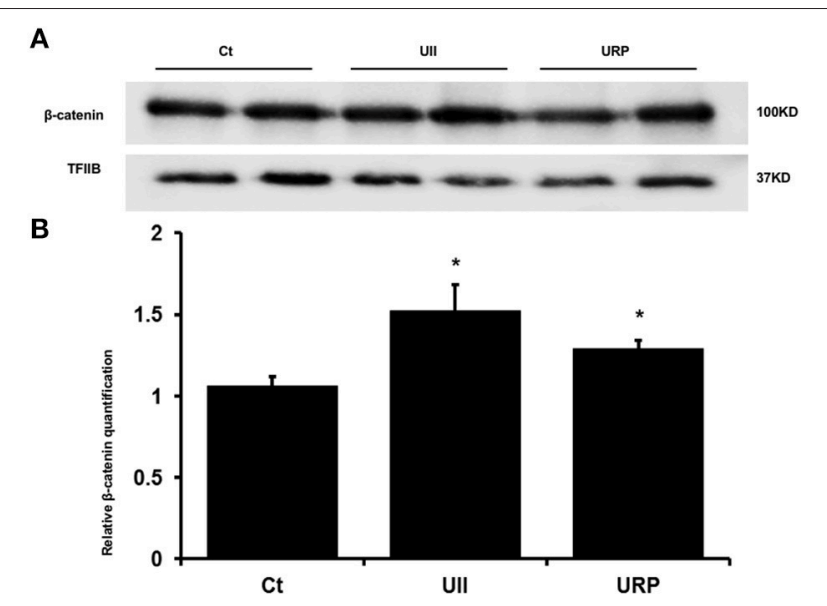

FIGURE 3 | UII and URP induce SMC nuclear translocation of $\beta$-catenin. SMCs were incubated in phosphate medium $(\mathrm{PI})$ in the presence and absence of $100 \mathrm{nM}$ UII or $100 \mathrm{nM}$ URP. Incubation of SMCs with UII and URP each significantly induced $\beta$-catenin nuclear translocation. Nuclear $\beta$-catenin protein expression was normalized to the expression of TFIIB (Transcription Factor IIB). ${ }^{\star} P<0.05$ ( $n=6$ per experiment). (A) Western blot visualization. (B) Relative $\beta$-catenin quantification normalized to the expression of TFIIB (Transcription Factor IIB).

effect on SMC calcification in the presence of phosphate media and that this effect was abolished in the presence of UT antagonist SB657510A. UII stimulation also increased ALP activity and a number of osteogenic mediators in SMCs in the presence of phosphate media. Together, these results suggest that the UII stimulates the osteogenic differentiation of SMCs, and suggest a role for the UII system in the pathology of carotid plaques.

To our knowledge, there is currently little evidence for the role of URP in any features of atherosclerosis, and this is the first study profiling its tissue expression in carotid atherosclerosis. The major difference in URP expression in stable compared to unstable plaques are that unstable plaques had significantly higher intensity in endothelial and foam cells. URP immunoreactivity was also very strong in osteoblasts, macrophages and lymphocytes and activated myointimal cells, however this was not significantly different in stable compared to unstable plaques. There is currently very little work on differential expression of UII and URP. Studies in mice have shown similar UII and URP expression in the nervous system, skeletal muscle, testes, vagina, and gall bladder, and differential expression in the seminal vesicles, heart, colon, and thymus (Dubessy et al., 2008). Another study of spontaneously hypertensive rats found elevated URP mRNA expression, suggesting a potential role for URP in spontaneous hypertension (Forty and Ashton, 2013). The differential cellular expression of URP in unstable vs. stable carotid atherosclerosis suggests that this may occur as either cause or effect in atherosclerotic disease and warrants further investigation.

We have previously demonstrated that UII and UT immunostaining is significantly elevated in atherosclerotic human carotid arteries compared to control, citing 


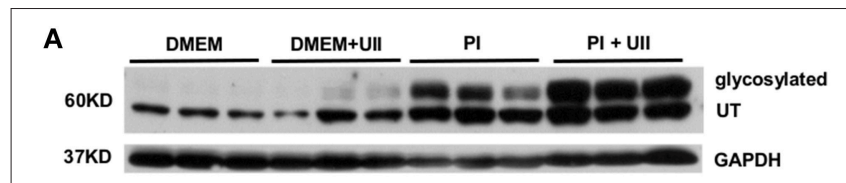

B

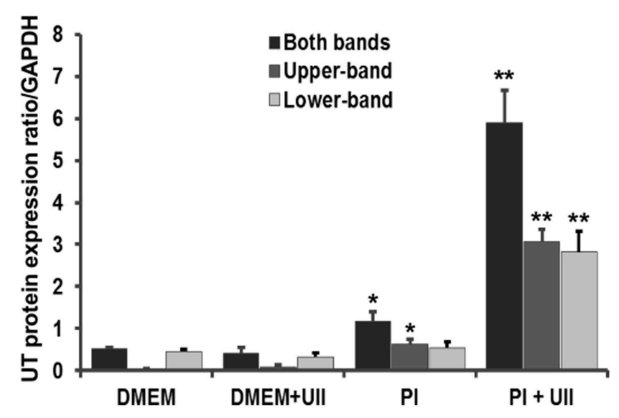

FIGURE 4 | Phosphate medium induces increased protein expression of UT. SMCs were incubated under one of the following conditions: DMEM alone, DMEM + $100 \mathrm{nM}$ Ull, phosphate medium (Pi) alone or phosphate medium (Pi) +100 nM UII. Two different degree of glycosylated UT (Upper-band and Lower-band) were detected around 6OKD in SMCs. Phosphate medium significantly increases the total UT and Upper-band compared to DMEM and DMEM + UII conditions, ${ }^{*} P<0.01$. Ull stimulation significantly increased UT expression in Pi medium compared to Pi medium alone ${ }^{\star \star} P<0.001$. $N=4$ for each condition. (A) Western blot visualization. (B) Relative UT quantification normalized to the expression of GAPDH.

immunoreactivity in endothelial, smooth muscle, and inflammatory cells (Bousette et al., 2004). In this study, we analyzed tissue expression relative to the stability of carotid plaques and found significantly elevated intensity in osteoblasts and medial SMCs in unstable compared to stable plaques. UII and UT immunoreactivities were also very strong in inflammatory cells of both stable and unstable plaques but since unstable plaques had significantly more inflammation, they had greater overall UII and UT immunostaining in these cells. Given that unstable plaques are associated with increased inflammation and release of cytokines, it is reasonable to assume that the increase in UII and UT is driven by inflammatory cytokines such as IL-6, previously shown to induce the expression of these molecules (Zhou et al., 2012). Further investigations using animal models of unstable plaques are needed to determine the exact role of UII and UT in atherosclerotic plaque stability.

ELISA measurements of plasma UII levels in the carotid endarterectomy patients revealed elevated plasma UII compared to controls; however, there was no significant difference between plasma UII levels in stable and unstable patients. We found significant positive correlations between plasma UII and age, BMI, triglycerides, and systolic blood pressure, and significant negative correlations with $\mathrm{HDL}$ and total cholesterol. Our findings are consistent with previous studies in hypertensive carotid endarterectomy demonstrating increased UII and association with BMI, age and systolic blood pressure (Cheung et al., 2004; Chen et al., 2009). The inverse correlation between serum UII and total cholesterol and HDL can be attributed to statin use in patients with carotid endarterectomy,

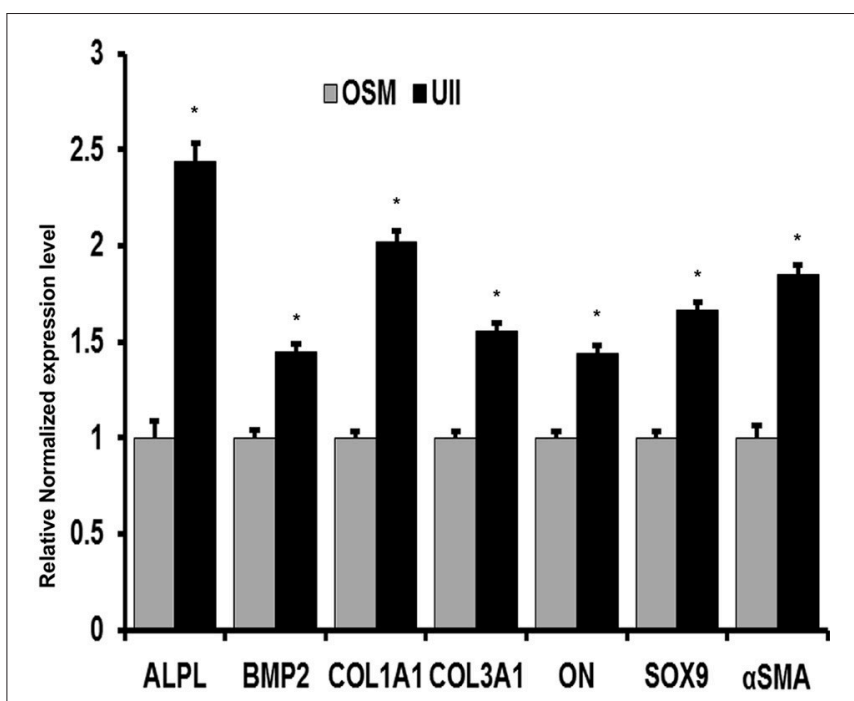

FIGURE 5 | UII stimulation of SMCs induces expression of osteogenic markers. SMCs in phosphate medium (PI) were incubated with $200 \mathrm{nM}$ UII for $24 \mathrm{~h}$ and expression of ALPL, BMP2, osteonectin, SOX9, collagen 1A1, collagen $3 A 1$, and $\alpha$-smooth muscle cell actin were assessed by Real time qPCR. Relative gene expression level was calculated against GAPDH level, and data is presented as fold change of relative interested gene expression in UII treated (UII). ${ }^{\star} P<0.01$ ( $n=4$ per experiment).

and further supported by our previous findings in experimental animals (You et al., 2012, 2014). Our findings that plasma UII is elevated in carotid atherosclerosis but not significantly different in stable compared to unstable patients demonstrate the importance of looking at tissue expression of UII and associated proteins to get better insight into their roles in the pathogenesis of carotid atherosclerosis.

This is the first study showing direct effects of UII and URP on SMC calcification and osteogenic differentiation. Vascular calcification occurs in very advanced atherosclerotic lesions and is a marker for atherosclerosis associated with several cardiovascular pathologies including hypertension, congestive heart failure, cardiac hypertrophy and ischemia and increased risk of myocardial infarction and stroke (Johnson et al., 2006; Demer and Tintut, 2008). It has been previously demonstrated that translocation of $\beta$-catenin and expression of skeletal morphogen BMP2 mediate the osteogenic differentiation of activated SMCs and this plays a crucial role in atherosclerotic calcification (Boström et al., 1993; Montes de Oca et al., 2014). Additionally, other osteogenic markers, osteonectin and SOX9, have also been localized to atherosclerotic plaques suggesting roles for them in the pathological calcification (Aigner et al., 2008; Farrokhi et al., 2014). Here, we demonstrate that UII and URP, in the presence of phosphate medium, stimulate calcium deposition in SMCs. Furthermore, UII increased ALP activity, $\beta$-catenin translocation, and increased expression of $A L P L, B M P 2, O N$, and SOX9, thus indicating osteogenic differentiation. Importantly, we found that phosphate medium alone or with UII increased UT protein expression, thus providing support for an important role for the UII system in vascular calcification. 
Limitations of this study: Increasing the number of patients included in the UII ELISA study may reveal differences in serum UII in patients with stable compared to unstable plaques. Additionally, further investigations should include the correlation of urotensin II levels with both tissue and serum levels of mediators of SMC osteogenic differentiation. Finally, the fact that our study only addresses the relationship between UII, URP and UT with atherosclerotic intimal calcification without any investigation of medial vascular calcification that is commonly seen in ESRD, diabetes, and elderly populations.

In summary, the present study demonstrates for the first time two important findings; first, local expression of the UII system in unstable carotid plaques is significantly higher than in stable plaques, and second, in vitro UII in the presence of phosphate medium induces ALP activity, $\beta$ catenin translocation, osteogenic transdifferentiation and ectopic calcium deposition in SMCs. A role for UII in inflammation (Liang et al., 2013), angiogenesis (Spinazzi et al., 2006), and increased release of metalloproteases (Zhou et al., 2012) has previously been established. Interestingly, atherosclerotic plaque instability is associated with increased inflammation

\section{REFERENCES}

Affolter, J., and Webb, D. J. (2001). Urotensin ii: A new mediator in cardiopulmonary regulation? Lancet 358, 774-775. doi: 10.1016/S01406736(01)06005-6

Aigner, T., Neureiter, D., Câmpean, V., Soder, S., and Amann, K. (2008). Expression of cartilage-specific markers in calcified and non-calcified atherosclerotic lesions. Atherosclerosis 196, 37-41. doi: 10.1016/j.atherosclerosis.2007.01.020

Al Kindi, H., Hafiane, A., You, Z., Albanese, I., Pilote, L., Genest, J., et al. (2014). Circulating levels of the vasoactive peptide urotensin ii in patients with acute coronary syndrome and stable coronary artery disease. Peptides 55, 151-157. doi: $10.1016 /$ j.peptides.2014.03.004

Ames, R. S., Sarau, H. M., Chambers, J. K., Willette, R. N., Aiyar, N. V., Romanic, A. M., et al. (1999). Human urotensin-ii is a potent vasoconstrictor and agonist for the orphan receptor gpr14. Nature 401, 282-286. doi: 10.1038/45809

Boström, K., Watson, K. E., Horn, S., Wortham, C., Herman, I. M., and Demer, L. L. (1993). Bone morphogenetic protein expression in human atherosclerotic lesions. J. Clin. Invest. 91, 1800-1809. doi: 10.1172/JCI116391

Bousette, N., Hu, F., Ohlstein, E. H., Dhanak, D., Douglas, S. A., and Giaid, A. (2006a). Urotensin-ii blockade with sb-611812 attenuates cardiac dysfunction in a rat model of coronary artery ligation. J. Mol. Cell. Cardiol. 41, 285-295. doi: 10.1016/j.yjmcc.2006.05.008

Bousette, N., Patel, L., Douglas, S. A., Ohlstein, E. H., and Giaid, A. (2004). Increased expression of urotensin ii and its cognate receptor gpr14 in atherosclerotic lesions of the human aorta. Atherosclerosis 176, 117-123. doi: 10.1016/j.atherosclerosis.2004.03.023

Bousette, N., Pottinger, J., Ramli, W., Ohlstein, E. H., Dhanak, D., Douglas, S. A., et al. (2006b). Urotensin-ii receptor blockade with sb-611812 attenuates cardiac remodeling in experimental ischemic heart disease. Peptides 27, 2919-2926. doi: 10.1016/j.peptides.2006.06.011

Chen, Y. H., Yandle, T. G., Richards, A. M., and Palmer, S. C. (2009). Urotensin ii immunoreactivity in the human circulation: evidence for widespread tissue release. Clin. Chem. 55, 2040-2048. doi: 10.1373/clinchem.2009.131748

Cheung, B. M., Leung, R., Man, Y. B., and Wong, L. Y. (2004). Plasma concentration of urotensin ii is raised in hypertension. J. Hypertens. 22, 1341-1344. doi: 10.1097/01.hjh.0000125452.28861.f1

Coulouarn, Y., Lihrmann, I., Jegou, S., Anouar, Y., Tostivint, H., Beauvillain, J. C., et al. (1998). Cloning of the cdna encoding the urotensin ii precursor in frog and human reveals intense expression of the urotensin ii gene in
(Shah, 2014), angiogenesis (Lam et al., 2013), and extracellular matrix protein degradation (Liu et al., 2014). Therefore, the present findings suggest that initially UII contribute to vascular calcification, however, sustained production and release of the peptide could contribute to plaque instability.

\section{AUTHOR CONTRIBUTIONS}

All authors contribute to design, analysis, and writing of this work. IA, BY, ZY performed experiments.

\section{ACKNOWLEDGMENTS}

This work was supported by the Canadian Institute of Health Research and the Heart and Stroke Foundation of Quebec.

\section{SUPPLEMENTARY MATERIAL}

The Supplementary Material for this article can be found online at: http://journal.frontiersin.org/article/10.3389/fphar. 2016.00149 motoneurons of the spinal cord. Proc. Natl. Acad. Sci. U.S.A. 95, 15803-15808. doi: 10.1073/pnas.95.26.15803

Dai, H. Y., Guo, X. G., Ge, Z. M., Li, Z. H., Yu, X. J., Tang, M. X., et al. (2008). Elevated expression of urotensin ii and its receptor in diabetic cardiomyopathy. J. Diabetes Complicat. 22, 137-143. doi: 10.1016/j.jdiacomp.2006.10.008

Demer, L. L., and Tintut, Y. (2008). Vascular calcification: Pathobiology of a multifaceted disease. Circulation 117, 2938-2948. doi: 10.1161/CIRCULATIONAHA.107.743161

Douglas, S. A., Sulpizio, A. C., Piercy, V., Sarau, H. M., Ames, R. S., Aiyar, N. V., et al. (2000). Differential vasoconstrictor activity of human urotensin-ii in vascular tissue isolated from the rat, mouse, dog, pig, marmoset and cynomolgus monkey. Br. J. Pharmacol. 131, 1262-1274. doi: 10.1038/sj.bjp.0703690

Douglas, S. A., Tayara, L., Ohlstein, E. H., Halawa, N., and Giaid, A. (2002). Congestive heart failure and expression of myocardial urotensin ii. Lancet 359, 1990-1997. doi: 10.1016/S0140-6736(02)08831-1

Dschietzig, T., Bartsch, C., Pregla, R., Zurbrügg, H. R., Armbruster, F. P., Richter, C., et al. (2002). Plasma levels and cardiovascular gene expression of urotensinii in human heart failure. Regul. Pept. 110, 33-38. doi: 10.1016/S01670115(02)00158-1

Dubessy, C., Cartier, D., Lectez, B., Bucharles, C., Chartrel, N., Montero-Hadjadje, M., et al. (2008). Characterization of urotensin ii, distribution of urotensin ii, urotensin ii-related peptide and ut receptor mrnas in mouse: Evidence of urotensin ii at the neuromuscular junction. J. Neurochem. 107, 361-374. doi: 10.1111/j.1471-4159.2008.05624.x

Elshourbagy, N. A., Douglas, S. A., Shabon, U., Harrison, S., Duddy, G., Sechler, J. L., et al. (2002). Molecular and pharmacological characterization of genes encoding urotensin-ii peptides and their cognate g-protein-coupled receptors from the mouse and monkey. Br. J. Pharmacol. 136, 9-22. doi: 10.1038/sj.bjp.0704671

Farrokhi, E., Samani, K. G., and Chaleshtori, M. H. (2014). Oxidized lowdensity lipoprotein and upregulated expression of osteonectin and bone sialoprotein in vascular smooth muscle cells. Lab. Med. 45, 297-301. doi: 10.1309/LMUJWVQFW6CJMSOQ

Forty, E. J., and Ashton, N. (2013). The urotensin system is up-regulated in the pre-hypertensive spontaneously hypertensive rat. PLOS ONE 8:e83317. doi: 10.1371/journal.pone.0083317

Itoh, H., McMaster, D., and Lederis, K. (1988). Functional receptors for fish neuropeptide urotensin ii in major rat arteries. Eur. J. Pharmacol. 149, 61-66. doi: $10.1016 / 0014-2999(88) 90042-8$ 
Johnson, R. C., Leopold, J. A., and Loscalzo, J. (2006). Vascular calcification: pathobiological mechanisms and clinical implications. Circ. Res. 99, 1044-1059. doi: 10.1161/01.RES.0000249379.55535.21

Lam, M. K., Al-Ansari, S., van Dam, G. M., Tio, R. A., Breek, J. C., Slart, R. H., et al. (2013). Single-chain vegf/cy5.5 targeting vegf receptors to indicate atherosclerotic plaque instability. Mol. Imaging Biol. 15, 250-261. doi: 10.1007/s11307-012-0594-7

Liang, D. Y., Liu, L. M., Ye, C. G., Zhao, L., Yu, F. P., Gao, D. Y., et al. (2013). Inhibition of uii/utr system relieves acute inflammation of liver through preventing activation of nf-kappab pathway in alf mice. PLoS ONE 8:e64895. doi: 10.1371/journal.pone.0064895

Libby, P. (2012). Inflammation in atherosclerosis. Arterioscler. Thromb. Vasc. Biol. 32, 2045-2051. doi: 10.1161/ATVBAHA.108.179705

Liu, X. Q., Mao, Y., Wang, B., Lu, X. T., Bai, W. W., Sun, Y. Y., et al. (2014). Specific matrix metalloproteinases play different roles in intraplaque angiogenesis and plaque instability in rabbits. PLOS ONE 9:e107851. doi: 10.1371/journal.pone.0107851

Lovett, J. K., Gallagher, P. J., Hands, L. J., Walton, J., and Rothwell, P. M. (2004). Histological correlates of carotid plaque surface morphology on lumen contrast imaging. Circulation 110, 2190-2197. doi: 10.1161/01.CIR.0000144307.82502.32

Lusis, A. J. (2000). Atherosclerosis. Nature 407, 233-241. doi: 10.1038/35025203

Montes de Oca, A., Guerrero, F., Martinez-Moreno, J. M., Madueño, J. A., Herencia, C., Peralta, A., et al. (2014). Magnesium inhibits wnt/beta-catenin activity and reverses the osteogenic transformation of vascular smooth muscle cells. PLoS ONE 9:e89525. doi: 10.1371/journal.pone.0089525

Pearson, D., Shively, J. E., Clark, B. R., Geschwind, I. I., Barkley, M., Nishioka, R. S., et al. (1980). Urotensin ii: A somatostatin-like peptide in the caudal neurosecretory system of fishes. Proc. Natl. Acad. Sci. U.S.A. 77, 5021-5024. doi: $10.1073 /$ pnas.77.8.5021

Prosser, H. C., Forster, M. E., Richards, A. M., and Pemberton, C. J. (2008). Urotensin ii and urotensin ii-related peptide (urp) in cardiac ischemiareperfusion injury. Peptides 29, 770-777. doi: 10.1016/j.peptides.2007.08.013

Ross, B., McKendy, K., and Giaid, A. (2010). Role of urotensin ii in health and disease. Am. J. Physiol. Regul. Integr. Comp. Physiol. 298, R1156-R1172. doi: 10.1152/ajpregu.00706.2009

Shah, P. K. (2014). Biomarkers of plaque instability. Curr. Cardiol. Rep. 16, 547. doi: 10.1007/s11886-014-0547-7

Shao, J. S., Cheng, S. L., Sadhu, J., and Towler, D. A. (2010). Inflammation and the osteogenic regulation of vascular calcification: A review and perspective. Hypertension 55, 579-592. doi: 10.1161/HYPERTENSIONAHA.109.134205

Simpson, C. M., Penny, D. J., Stocker, C. F., and Shekerdemian, L. S. (2006). Urotensin ii is raised in children with congenital heart disease. Heart 92, 983-984. doi: 10.1136/hrt.2005.074039

Spinazzi, R., Albertin, G., Nico, B., Guidolin, D., Di Liddo, R., Rossi, G. P., et al. (2006). Urotensin-ii and its receptor (ut-r) are expressed in rat brain endothelial cells, and urotensin-ii via ut-r stimulates angiogenesis in vivo and in vitro. Int. J. Mol. Med. 18, 1107-1112. doi: 10.3892/ijmm.18.6.1107
Stary, H. C., Chandler, A. B., Dinsmore, R. E., Fuster, V., Glagov, S., Insull, W. Jr., et al. (1995). A definition of advanced types of atherosclerotic lesions and a histological classification of atherosclerosis. A report from the committee on vascular lesions of the council on arteriosclerosis, american heart association. Arterioscler. Thromb. Vasc. Biol. 15, 1512-1531.

Störk, S., van den Beld, A. W., von Schacky, C., Angermann, C. E., Lamberts, S. W., Grobbee, D. E., et al. (2004). Carotid artery plaque burden, stiffness, and mortality risk in elderly men: A prospective, population-based cohort study. Circulation 110, 344-348. doi: 10.1161/01.CIR.0000134966. 10793.C9

Tsaousi, A., Mill, C., and George, S. J. (2011). The wnt pathways in vascular disease: Lessons from vascular development. Curr. Opin. Lipidol. 22, 350-357. doi: 10.1097/MOL.0b013e32834aa701

Watson, A. M., Olukman, M., Koulis, C., Tu, Y., Samijono, D., Yuen, D., et al. (2013). Urotensin ii receptor antagonism confers vasoprotective effects in diabetes associated atherosclerosis: Studies in humans and in a mouse model of diabetes. Diabetologia 56, 1155-1165. doi: 10.1007/s00125-013-2837-9

You, Z., Al Kindi, H., Abdul-Karim, A., Barrette, P. O., and Schwertani, A. (2014). Blocking the urotensin ii receptor pathway ameliorates the metabolic syndrome and improves cardiac function in obese mice. FASEB J. 28, 1210-1220. doi: 10.1096/fj.13-236471

You, Z., Genest, J. Jr., Barrette, P. O., Hafiane, A., Behm, D. J., D’OrleansJuste, P., et al. (2012). Genetic and pharmacological manipulation of urotensin ii ameliorate the metabolic and atherosclerosis sequalae in mice. Arterioscler. Thromb. Vasc. Biol. 32, 1809-1816. doi: 10.1161/ATVBAHA.112. 252973

Yusuf, S., Ounpuu, S., and Anand, S. (2002). The global epidemic of atherosclerotic cardiovascular disease. Med. Princ. Pract. 11(Suppl. 2), 3-8. doi: 10.1159/ 000066416

Zhang, L., Ding, R., Zhen, Y., and Wu, Z. G. (2009). Relation of urotensin ii levels to lone atrial fibrillation. Am. J. Cardiol. 104, 1704-1707. doi: 10.1016/j.amjcard.2009.07.053

Zhou, C. H., Wan, Y. Y., Chu, X. H., Song, Z., Xing, S. H., Wu, Y. Q., et al. (2012). Urotensin ii contributes to the formation of lung adenocarcinoma inflammatory microenvironment through the nf-kappab pathway in tumorbearing nude mice. Oncol. Lett. 4, 1259-1263. doi: 10.3892/ol.2012.932

Conflict of Interest Statement: The authors declare that the research was conducted in the absence of any commercial or financial relationships that could be construed as a potential conflict of interest.

Copyright (C) 2016 Albanese, Daskalopoulou, Yu, You, Genest, Alsheikh-Ali and Schwertani. This is an open-access article distributed under the terms of the Creative Commons Attribution License (CC BY). The use, distribution or reproduction in other forums is permitted, provided the original author(s) or licensor are credited and that the original publication in this journal is cited, in accordance with accepted academic practice. No use, distribution or reproduction is permitted which does not comply with these terms. 